\title{
Polymorphisms in the bovine lactoferrin promoter are associated with reproductive performance and somatic cell count
}

\author{
F. O’Halloran, ${ }^{\star}$ D. P. Berry,† B. Bahar,ł D. J. Howard,§ T. Sweeney,‡ and L. Giblin*¹ \\ *Teagasc, Moorepark Food Research Centre, Fermoy, Co. Cork, Ireland \\ †Teagasc, Moorepark Dairy Production Research Centre, Fermoy, Co. Cork, Ireland \\ ‡School of Agriculture, Food Science and Veterinary Medicine, University College Dublin, Belfield, Dublin 4, Ireland \\ §Teagasc, Animal Production Research Centre, Mellows Campus, Athenry, Co. Galway, Ireland
}

\begin{abstract}
Lactoferrin plays an important role in the innate immune system, with well-characterized antibacterial, antiviral, and immune modulatory properties. The objective of this study was to determine the allele and haplotype frequency of polymorphisms at positions $-586,-190$, and -28 of the bovine lactoferrin promoter in Holstein-Friesians and to quantify their association with performance using phenotypic data on progeny from 848 sires. Associations between genotypes and performance were quantified using weighted mixed models with genotyped individuals included as a random effect, and average expected relationships among individuals accounted for through a numerator relationship matrix. The dependent variables were daughter yield deviation for production traits and deregressed predicted transmitting ability for calving interval and functional survival. The $\mathrm{C}$ to $\mathrm{T}$ polymorphism at -586 , which distorts a putative activating protein 2 (AP-2) binding site, was associated with a shorter calving interval and higher somatic cell score. The G to A polymorphism at -190 , located in a putative selective promoter factor 1 (SP-1) binding site, was associated with a longer calving interval and decreased functional survival. A third polymorphism (A to $\mathrm{C}$ ) at position -28 , found within the noncanonical TATA box, had a tendency to associate with functional survival. On the basis of the data we proposed a haplotype combination that was associated with improved reproductive performance in the Holstein-Friesian breed. We hypothesized that the observable phenotypic associations with lactoferrin promoter polymorphisms can potentially be explained by allele-specific differences in constitutive or inducible levels of gene expression. The lack of a pleiotropic effect of the single nucleotide polymorphisms studied on both fertility and milk production traits strengthens
\end{abstract}

Received September 3, 2009.

Accepted November 10, 2009.

${ }^{1}$ Corresponding author: linda.giblin@teagasc.ie the importance of these polymorphisms, or at least the lactoferrin promoter, in selection for improved fertility. Key words: lactoferrin, Holstein, reproduction, polymorphism

\section{INTRODUCTION}

Lactoferrin is a glycosylated protein noted primarily for its iron homeostasis, antibacterial, antiviral, and immune modulatory properties (Gonzalez-Chavez et al., 2009). As an important innate immune protein, it is found in neutrophil granules and a wide variety of secretions, including colostrum, milk, vaginal fluid, semen, tears, saliva, nasal secretions, bile, and gastrointestinal fluids.

Lactoferrin gene expression is both constitutive and inducible and is species-, tissue-, and cell-type-specific (Wang et al., 1997; Teng, 2002; Zheng et al., 2005). Its regulation is complex, responding to hormone levels, pathogen assault, cell developmental stage, and diet (Close et al., 1997; Teng et al., 2002b; Wang et al., 2005; Nakajima et al., 2008; Li et al., 2009). The bovine lactoferrin gene maps to BTA22 and includes 17 exons that code for a polypeptide chain of 708 amino acids (Seyfert et al., 1994). Its promoter contains a noncanonical TATA box at -25 bp within a GC-rich region (Zheng et al., 2005). Deletion construct analysis has indicated that the minimal requirement for basal transcription stretches -543 nucleotides upstream from the transcription start site. Multiple repeat elements and putative binding sites for steroid hormones, infection responsive transcription factors, cellular differentiation transcription factors, and metal regulatory elements are noteworthy features along its length (Figure 1). To date, studies in other species have confirmed that the transcription factor selective promoter factor 1 (SP-1) and estrogen receptor $\alpha$ attach to the lactoferrin promoter (Wang et al., 1998; Teng et al., 2002b). In addition, activating protein 2 (AP-2) and signal transducer and activator of transcription 5 (STAT5) binding matrices are also functional, as evidenced by electrophoretic mobility shift assays with nuclear extracts in porcine studies (Wang et al., 1998). 


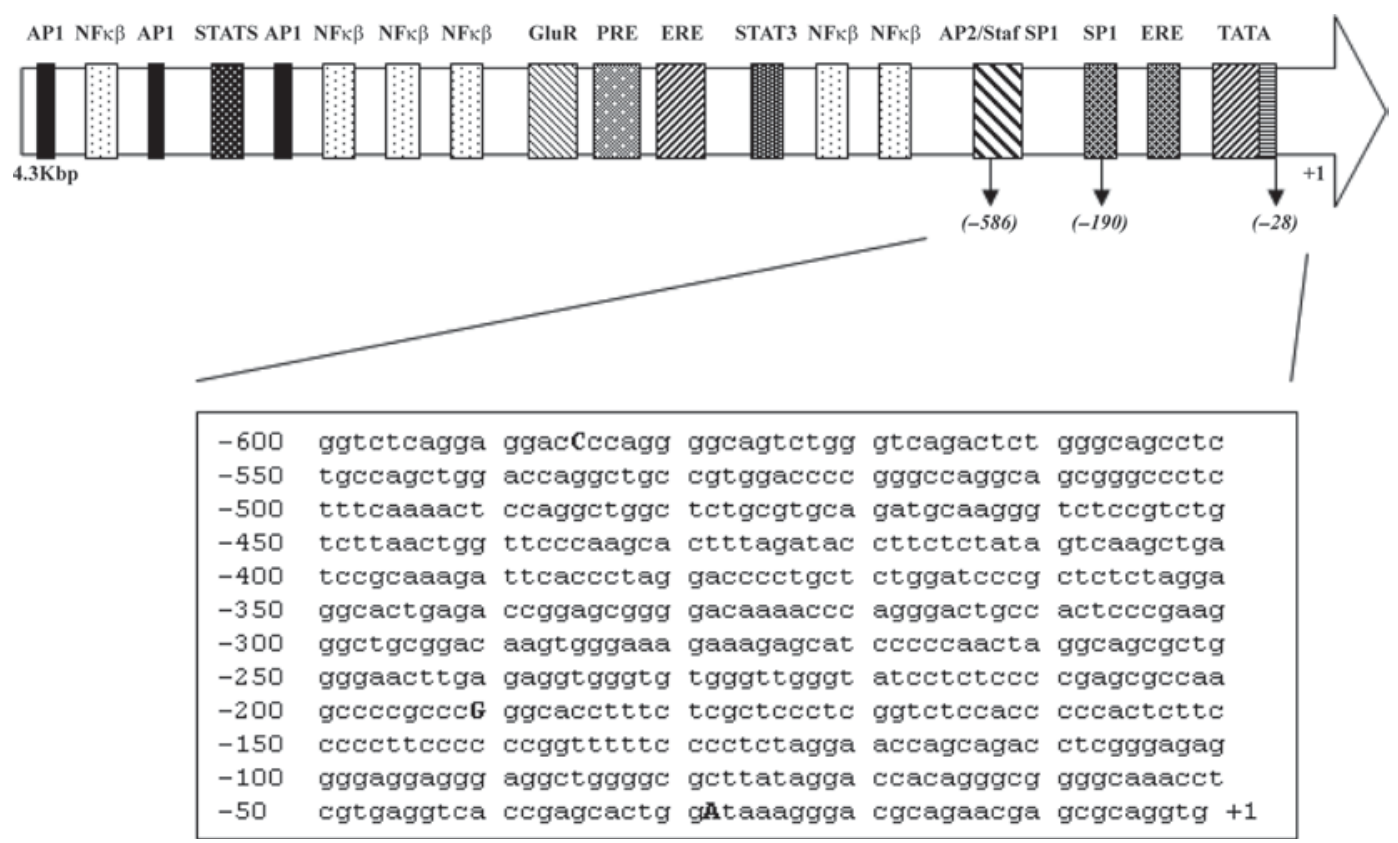

Figure 1. Partial $(4.3 \mathrm{~kb})$ promoter region of the bovine lactoferrin gene. Boxed regions represent putative binding sites for transcription factors and steroid response elements relative to the transcription start site $(+1)$ : TATA box, estrogen response element (ERE), selective promoter factor 1 (SP1), selenocysteine tRNA gene transcription-activating factor (Staf), activating protein 2 (AP-2), nuclear factor kappa- $\beta$ (NF- $\kappa \beta$ ), signal transducer and activator of transcription 3 (STAT3), progesterone response element (PRE), glucocorticoid receptor (GluR), activating protein 1 (AP-1), and signal transducer and activator of transcription 5 (STAT5). The nucleotide sequence of $600 \mathrm{bp}$ of the 5 ' flanking region of the bovine lactoferrin gene (GenBank accession No. NC_007320) is boxed with the polymorphic sites $-586,-190$, and -28 bp capitalized and in bold font.

Numerous polymorphisms have been identified in the bovine lactoferrin promoter (Li et al., 2004; Daly et al., 2006; Kamiński et al., 2006; O'Halloran et al., 2009). In this association study, 3 polymorphisms were selected based on their location within predicted transcriptional factor binding sites or within the basal transcriptional matrix. The $\mathrm{C}$ to $\mathrm{T}$ polymorphism at position -586 (Lf-586) lies within a consensus sequence for the transcription factor AP-2 (Daly et al., 2006), which is known to play a role in mammary development, lactogenesis, and milk protein secretion (Malewski et al., 2002; Jager et al., 2003; Zhang et al., 2003).

The second polymorphism, which results in a $\mathrm{G}$ to A substitution at position -190 (Lf-190), lies within a GC-rich putative SP-1 site neighboring an estrogen response element (O'Halloran et al., 2009); SP-1 is thought to participate in the basal transcriptional apparatus of the bovine lactoferrin promoter (Zheng et al., 2005). It also plays an important role in estrogen responsive genes, with mutations in GC-rich SP-1 sites resulting in the loss of estrogen activation (Safe and Kim, 2008).

An $\mathrm{A}$ to $\mathrm{C}$ polymorphism at position -28 (Lf-28) is located in the basal transcriptional apparatus (Daly et al., 2006; O'Halloran et al., 2009). The introduction of a $\mathrm{C}$ nucleotide at this site deviates from the TA-rich sequence of the TATA box, which has the potential to alter basal levels of lactoferrin.

The aim of this study was to quantify the association between these $3 \mathrm{SNP}$ in the lactoferrin promoter and performance traits in Holstein-Friesian dairy cattle.

\section{MATERIALS AND METHODS}

\section{Study Population, DNA Extraction, and Genotyping}

Genomic DNA was isolated from semen straws of 848 Holstein-Friesian sires. This study group represents the germplasm in Irish dairy herds in recent years. The average co-ancestry among the 848 sires was $2.2 \%$. DNA from semen straws was extracted using the following procedure. The semen was washed twice in PBS $(\mathrm{pH}$ 7.4), and cell pellets were harvested by centrifugation and resuspended in $450 \mu \mathrm{L}$ of prewarmed extraction buffer (10 m $M$ Tris, pH 8; $10 \mathrm{~m} M$ EDTA, pH 8.0; $1 \%$ SDS; $100 \mathrm{mM} \mathrm{NaCl}$ ). Then, $15 \mu \mathrm{L}$ of 2 -mercaptoethanol was added. Samples were incubated at $55^{\circ} \mathrm{C}$ for $15 \mathrm{~min}$ followed by the addition of $10 \mu \mathrm{L}$ of proteinase $\mathrm{K}(20$ $\mathrm{mg} / \mathrm{mL}$ ). Lysis occurred following an overnight incubation at $60^{\circ} \mathrm{C}$. DNA was extracted using the Maxwell instrument (Promega Corp., Madison, WI) according to the manufacturer's instructions. The SNP genotyp- 
Table 1. Lactoferrin promoter SNP, genotype frequency, minor allele frequency (MAF), and significance of deviation for Hardy-Weinberg equilibrium (HWE)

\begin{tabular}{lllccc}
\hline SNP & & Genotype & $\begin{array}{c}\text { Genotype } \\
\text { frequency }\end{array}$ & MAF & HWE \\
\hline Lf-28 & BTA22 position & AA & 0.57 & 0.26 & $P=0.002$ \\
& 54313902 & AC & 0.34 & & \\
Lf-190 & \multirow{2}{*}{54313740} & CC & 0.09 & & \\
& & GG & 0.63 & 0.21 & $P=0.25$ \\
Lf-586 & GA & 0.32 & & \\
& \multirow{2}{*}{54313344} & GA & 0.05 & 0.14 & $P<0.1 \times 10^{-5}$ \\
& & CC & 0.77 & & \\
\hline
\end{tabular}

${ }^{1}$ SNP submitted to the National Center for Biotechnology Information SNP database.

ing analysis was performed by Sequenom using the iPLEX Gold assay on a MassARRAY platform (www. sequenom.com). As a quality control measure, genomic DNA representing 25 animals was genotyped in duplicate for each SNP. Concordance across SNP and all duplicates was $100 \%$.

\section{Genotypic and Phenotypic Data}

Summary statistics of lactoferrin SNP genotypes and allele frequencies are detailed in Table 1. A measure of linkage disequilibrium $\left(\mathrm{r}^{2}\right.$; Hill and Robertson, 1968) was calculated between each pair-wise combination of the 3 SNP. The Phase V2.1 software for haplotype estimation (Stephens et al., 2001; Stephens and Donnelly, 2003) was used to reconstruct haplotype probabilities for the 3 segregating SNP (Table 1). Daughter yield deviations (DYD) and PTA, as well as associated reliabilities for a range of performance traits evaluated by the Irish Cattle Breeding Federation in January 2009, were available for inclusion in the analysis. Models used in genetic evaluations in Ireland, as well as variance components, are outlined by Berry et al. (2007). Daughter yield deviations for 305-d milk, fat, and protein yields as well as geometric mean SCS $\left(\log _{\mathrm{e}} \mathrm{SCS}\right)$ are estimated in Ireland using a repeatability animal model across the first 5 lactations. The DYD expressed on the scale of PTA were used in this study. The PTA for calving interval and survival were estimated using a multi-trait animal model, including data from the first 3 lactations. The PTA for milk yield is used to adjust survival for differences in genetic merit of milk yield; hence, this survival trait is functional survival. The PTA were deregressed using the procedure outlined by Berry et al. (2009). Parental contribution to the reliability of each DYD or PTA was removed using the approach of Harris and Johnson (1998), and only sires with a reliability, less parental contribution, of $>60 \%$ were retained for inclusion in the association analysis.
A total of 742 sires fulfilled these criteria for inclusion in the analysis of milk, fat, and protein yields as well as milk fat and protein concentrations; the number of sires included in the association analysis with SCS, calving interval, and survival was 703, 501, and 477, respectively.

\section{Analysis}

The association between each SNP and performance was quantified using weighted mixed models in ASREML (Gilmour et al., 2009) with individual included as a random effect, and average expected relationships among individuals accounted for through the numerator relationship matrix. Year of birth (divided into 5 yearly intervals) and percentage Holstein of the individual sire were included as fixed effects in the model. In all instances the dependent variable was DYD for milk yield, fat yield, protein yield, and SCS, and deregressed PTA for calving interval and survival, weighted by their respective reliability less the parental contribution. Each SNP was individually included in the model as either a class or a continuous variable corresponding to the number of copies of the T, A, and C allele for Lf-586, Lf-190, and Lf-28, respectively. In a separate analysis, the probability of each haplotype for the individual was included as a fixed effect in the weighted animal mixed model with year of birth of the bull and Holstein proportion included as fixed effects. The most frequent haplotype was not included in the model to avoid linear dependencies among haplotype effects. Significance of the associations was determined by the F-test and the appropriate degrees of freedom.

\section{RESULTS}

Table 1 summarizes the genotype and allele frequencies of all 848 Holstein-Friesian sires. The genotypes of Lf-586 and Lf-28 SNP deviated $(P<0.001)$ from 
Table 2. Association between a range of performance variables and (a) replacing a C allele with a T allele in the Lf-586 SNP (SE in parentheses) and (b) Lf-586 genotypes

\begin{tabular}{|c|c|c|c|c|c|c|}
\hline \multirow[b]{2}{*}{ Trait } & \multirow[b]{2}{*}{ Allele substitution } & \multirow[b]{2}{*}{$P$-value } & \multicolumn{3}{|c|}{ Genotype $^{1}$} & \multirow[b]{2}{*}{$P$-value } \\
\hline & & & $\mathrm{CC}$ & $\mathrm{CT}$ & $\mathrm{TT}$ & \\
\hline Fat yield $(\mathrm{kg})$ & $-0.62(0.51)$ & 0.22 & 0 & $-0.59(0.61)$ & $-1.32(1.40)$ & 0.47 \\
\hline Protein yield $(\mathrm{kg})$ & $-0.08(0.40)$ & 0.84 & 0 & $0.19(0.48)$ & $-0.93(1.10)$ & 0.58 \\
\hline Fat percentage $(\% \times 100)^{2}$ & $-0.67(1.07)$ & 0.53 & 0 & $-1.73(1.29)$ & $1.61(2.94)$ & 0.28 \\
\hline Protein percentage $(\% \times 100)^{2}$ & $0.26(0.52)$ & 0.62 & 0 & $-0.27(0.63)$ & $2.01(1.44)$ & 0.29 \\
\hline Survival (\%) & $0.27(0.18)$ & 0.13 & 0 & $0.23(0.22)$ & $0.65(0.48)$ & 0.30 \\
\hline
\end{tabular}

${ }^{1}$ Referent class is the CC genotype and is compared with the CT and TT genotype.

${ }^{2} \mathrm{~A}$ value of 1 , before multiplication by 100 , equates to 1 percentage unit.

Hardy-Weinberg equilibrium, with a marked deficiency in the TT and CC genotypes, respectively.

The associations among the segregating SNP Lf-586, Lf-190, and Lf-28, and performance are detailed in Tables 2, 3, and 4, respectively. According to results of the allele substitution effects, none of the 3 SNP investigated were associated with milk, fat, or protein yields or milk fat and protein concentration, although when included as a class effect in the model, Lf- 28 was associated $(P<0.05)$ with milk yield and protein yield (Table 4). The strength of the statistical association between all SNP and the nonproduction traits differed by SNP and model fit (i.e., genotype included in the model as either a continuous variable or a class variable). Although only approaching significance $(P<$ $0.10)$ in most instances, the T allele of the Lf- 586 SNP was associated with a shorter calving interval $(P=$ $0.08)$ but increased SCS $(P=0.07)$ (Table 2$)$. The A allele of the Lf-190 SNP was associated $(P<0.05)$ with a longer calving interval and reduced functional survival (Table 3). The Lf-190 SNP was not associated with SCS. The Lf-28 SNP had a tendency $(P<0.10)$ to be associated with functional survival (Table 4). The $\mathrm{CC}$ genotype, which associated with superior functional survival, also associated $(P=0.02)$ with greater SCS. A multiple regression model that included all 3 SNP indicated that the associations between both Lf- 586 and Lf190 and calving interval were additive. The strength of the association with calving interval for Lf-586 ( $b=$ $-0.98 ; \mathrm{SE}=0.45)$ and Lf-190 $(\mathrm{b}=0.68 ; \mathrm{SE}=0.31)$ was similar in strength to the univariate analyses.

Five haplotypes were reconstructed (posterior means of the frequency in parentheses) in the sequence of Lf-586, Lf-190, and Lf-28: CGA (53\%), CAA (21\%), TGC (13.5\%), CGC (12\%), and TGA (0.5\%). Linkage disequilibrium $\left(\mathrm{r}^{2}\right)$ between Lf-586 and Lf-190, between Lf-586 and Lf-28, and between Lf-190 and Lf-28 was $0.04,0.44$, and 0.09 , respectively. Table 5 lists the regression coefficients of the performance traits of the 5 different haplotypes. Association analysis indicated that sires with the $\mathrm{T}_{-586} \mathrm{G}_{-190} \mathrm{C}_{-28}$ haplotype had improved genetic merit for calving interval and survival compared with the $\mathrm{C}_{-586} \mathrm{~A}_{-190} \mathrm{~A}_{-28}$ haplotype.

\section{DISCUSSION}

Holstein-Friesian dairy cattle have been subjected to intense selection for milk production, which has result-

Table 3. Association between a range of performance variables and (a) replacing a $\mathrm{G}$ allele with an A allele in the Lf-190 SNP (SE in parentheses) and (b) Lf-190 genotypes

\begin{tabular}{|c|c|c|c|c|c|c|}
\hline \multirow[b]{2}{*}{ Trait } & \multirow[b]{2}{*}{ Allele substitution } & \multirow[b]{2}{*}{$P$-value } & \multicolumn{3}{|c|}{ Genotype $^{1}$} & \multirow[b]{2}{*}{$P$-value } \\
\hline & & & GG & GA & $\mathrm{AA}$ & \\
\hline Milk yield (kg) & $-5.93(11.49)$ & 0.60 & 0 & $-4.95(13.98)$ & $-13.64(27.24)$ & 0.87 \\
\hline Fat yield (kg) & $-0.28(0.41)$ & 0.49 & 0 & $0.18(0.50)$ & $-1.41(0.97)$ & 0.21 \\
\hline Protein yield $(\mathrm{kg})$ & $-0.21(0.32)$ & 0.51 & 0 & $-0.11(0.39)$ & $-0.60(0.76)$ & 0.73 \\
\hline Fat percentage $(\% \times 100)^{2}$ & $-0.03(0.87)$ & 1.00 & 0 & $0.79(1.06)$ & $-1.58(2.06)$ & 0.41 \\
\hline Protein percentage $(\% \times 100)^{2}$ & $0.10(0.42)$ & 0.82 & 0 & $0.25(0.52)$ & $-0.08(1.00)$ & 0.85 \\
\hline SCS $\left(\log _{e}\right.$ units $\left.\times 100\right)$ & $0.22(0.65)$ & 0.75 & 0 & $-0.14(0.94)$ & $2.32(1.83)$ & 0.36 \\
\hline Calving interval $(\mathrm{d})$ & $0.68(0.28)$ & 0.01 & 0 & $0.98(0.37)$ & $0.83(0.72)$ & 0.02 \\
\hline Survival $(\%)$ & $-0.39(0.16)$ & 0.02 & 0 & $-0.54(0.21)$ & $-0.69(0.39)$ & 0.04 \\
\hline
\end{tabular}

${ }^{1}$ Referent class is the GG genotype and is compared with the GA and AA genotype.

${ }^{2} \mathrm{~A}$ value of 1 , before multiplication by 100 , equates to 1 percentage unit. 
Table 4. Association between a range of performance variables and (a) replacing an A allele with a C allele in the Lf-28 SNP (SE in parentheses) and (b) Lf-28 genotypes

\begin{tabular}{|c|c|c|c|c|c|c|}
\hline \multirow[b]{2}{*}{ Trait } & \multirow[b]{2}{*}{ Allele substitution } & \multirow[b]{2}{*}{$P$-value } & \multicolumn{3}{|c|}{ Genotype $^{1}$} & \multirow[b]{2}{*}{$P$-value } \\
\hline & & & AA & $\mathrm{AC}$ & $\mathrm{CC}$ & \\
\hline Fat yield (kg) & $0.22(0.38)$ & 0.57 & 0 & $0.39(0.48)$ & $0.17(0.91)$ & 0.72 \\
\hline Protein yield (kg) & $0.21(0.30)$ & 0.48 & 0 & $0.78(0.38)$ & $-0.52(0.70)$ & 0.04 \\
\hline Fat percentage $(\% \times 100)^{2}$ & $0.00(0.81)$ & 1.00 & 0 & $-1.23(1.02)$ & $1.99(1.91)$ & 0.15 \\
\hline Protein percentage $(\% \times 100)^{2}$ & $-0.05(0.40)$ & 0.89 & 0 & $-0.37(0.50)$ & $0.42(0.94)$ & 0.58 \\
\hline Survival (\%) & $0.24(0.14)$ & 0.09 & 0 & $0.42(0.19)$ & $0.23(0.31)$ & 0.07 \\
\hline
\end{tabular}

${ }^{1}$ Referent class is the AA genotype and is compared with the AC and CC genotype.

${ }^{2} \mathrm{~A}$ value of 1 , before multiplication by 100 , equates to 1 percentage unit.

ed in system-wide structural and functional adaption (Walsh et al., 2007, 2008). This elite milk-producing phenotype has been at the expense of health (Weller and Ezra, 1997) and reproductive performance (Pryce and Veerkamp, 2001). In this study, 2 SNP (Lf-190 and Lf-586) independently associated with calving interval but did not associate with milk production traits.

Animals with the $\mathrm{T}_{-586} \mathrm{G}_{-190} \mathrm{C}_{-28}$ lactoferrin promoter haplotype had similar genetic merit for milk production but superior genetic merit for calving interval and functional survival compared with $\mathrm{C}_{-586} \mathrm{~A}_{-190} \mathrm{~A}_{-28}$ animals. Improving fertility is now a major challenge for dairy cattle breeding programs. For lowly heritable traits; for example, fertility (Liu et al., 2008), accuracy of selection and therefore genetic gain can be augmented by the use of genomic information, such as the association of the $\mathrm{T}_{-586} \mathrm{G}_{-190} \mathrm{C}_{-28}$ haplotype with calving interval. Calving interval is measured relatively late in the life of an animal or the animal's progeny. Because genotype can be recorded at birth, it has the potential to reduce the generation interval and fast-track genetic improvement. The lack of an antagonistic association between this haplotype and milk production further substantiates the benefit of this haplotype in a breeding program.

Homozygous AA at Lf-190 was associated with an increase in calving interval of $0.83 \mathrm{~d}$ and a reduction in survival of 0.69 percentage units. As reproductive performance contributes to premature culling (Olori et al., 2002), it is not surprising that AA sires with inferior genetic merit for calving interval had daughters that did not persevere in the dairy herd. The introduction of an A nucleotide at this locus altered the sequence of a putative SP1 binding site ( -201 to $-186 \mathrm{bp})$, located 139 nucleotides from an estrogen response element $(-47$ to $-28 \mathrm{bp}$; Zheng et al., 2005). Although Lf-190 may not be the causative mutation, one interpretation of its association with reproductive performance is that the mutation weakens the binding affinity for SP-1 at this locus. Binding of SP-1 proteins to hormone-sensitive promoters mediates estrogen regulation, with estrogen receptor $\alpha$ interacting with the C-terminal DNA binding domain of bound SP-1 allowing for transcriptional regulation (Safe and Kim, 2008). Although the expression of lactoferrin in the bovine reproductive tract has

Table 5. Regression coefficients (SE in parentheses) of the performance traits on the different haplotypes in the sequence of Lf-586, Lf-190, and Lf-28 SNP

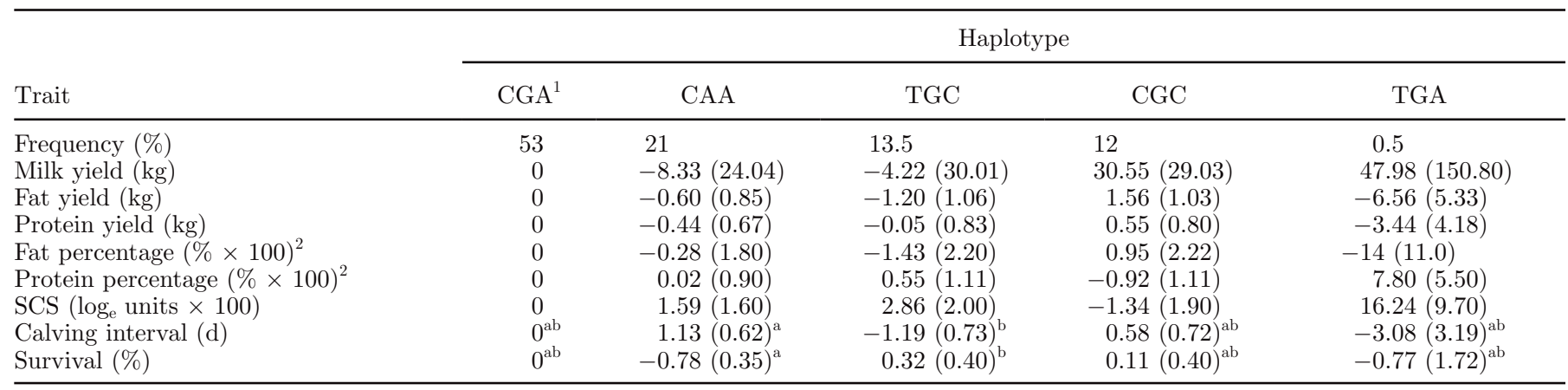

${ }^{\mathrm{a}, \mathrm{b}}$ Regression coefficients within a row with different superscript letters are different $(P<0.05)$.

${ }^{1}$ CGA haplotype is the referent haplotype.

${ }^{2} \mathrm{~A}$ value of 1 , before multiplication by 100 , equates to 1 percentage unit. 
not been determined, lactoferrin promoters in other species are known to be estrogen inducible (Teng et al., 2002a,b) and transcriptionally active in uterine tissue (Teng et al., 2002a; Kolm et al., 2006). The role of lactoferrin in endometrial tissue is unknown but, as an antimicrobial, it may aid in uterine clearance of pathogens that would otherwise hamper conception or pregnancy (King et al., 2003). Yanaihara et al. (2007) demonstrated that high fertilization rates and good embryo quality correlated with high lactoferrin concentrations in the follicular fluid of in vitro fertilization patients.

The $\mathrm{T}$ allele at locus -586 displayed antagonistic pleiotropy by favorably associating with calving interval but unfavorably associating with SCS. The deviation from Hardy-Weinberg equilibrium and the low frequency of the TT genotype (4\%) indicates that there is selection for the $\mathrm{C}$ allele, with the $\mathrm{CC}$ genotype predominating. The $\mathrm{T}$ nucleotide at position -586 results in a deviation from the consensus binding sequence for an AP-2 transcription factor (Eckert et al., 2005). Moreover, Lf-586 may not be the causative mutation for the associations observed, but the nucleotide substitution could potentially weaken the affinity for AP-2. Indeed, a polymorphism in an AP-2 site within the $\beta$-lactoglobulin promoter reduced binding affinity for AP-2, directly resulting in a decrease in secretion of $\beta$-lactoglobulin in bovine milk (Lum et al., 1997; Kuss et al., 2003). The Lf-586 SNP also lies within a selenocysteine tRNA gene transcription-activating factor (Staf) binding site; Staf is primarily involved in the biosynthesis of selenoproteins, which have supportive roles in lactation activity and mammary gland health (Adachi et al., 1999; Bruzelius et al., 2007). Interestingly, in a preliminary study, homozygous TT cows tended to have lower lactoferrin protein concentration in their milk over a lactation curve, compared with their CC herdmates (F. O'Halloran; unpublished data). In addition, transfection studies in mammary epithelial cells showed that a promoter variant that included the $\mathrm{T}$ allele had decreased basal transcriptional activity in vitro compared with a variant with the $\mathrm{C}$ allele (B. Bahar; unpublished results). Other lactoferrin promoter polymorphisms $(\mathrm{C}+32 \mathrm{G}, \mathrm{G}-478$ deletion, and $\mathrm{T}+72 \mathrm{C})$ have also shown associations with somatic cell data (Kamiński et al., 2006; Wang et al., 2009). However, in silico analysis did not identify transcriptional regulation matrices at these locations (Zheng et al., 2005), indicating that these SNP may not be causal mutations.

Associations of Lf-586 with calving interval could also be explained by deviation from the putative AP-2 binding sequence. The GC-rich regions characteristic of AP-2 sites often overlap with SP-1 sites (Johnson and Jameson, 1999; Lopes et al., 2006). It will be interest- ing to determine if the $\mathrm{T}$ mutation at Lf-586 allows promiscuous SP-1 proteins to bind, and together with estrogen, upregulate lactoferrin expression in the reproductive tract.

The associations of Lf-28 genotype to milk yield, protein yield, and SCS disagreed with allele substitution effects. These disagreements may (a) be a phenomenon of the mathematical properties of the models used (i.e., there was a low frequency of the CC genotype); (b) be an effect of dominance; or (c) indicate that Lf-28 is not the causative mutation but is in weak to moderate linkage disequilibrium with the causative mutation.

We hypothesize that the observable phenotypic associations with Lf-190 and Lf-586 can potentially be explained by allele-specific differences in lactoferrin gene expression as a result of sequence deviation in transcription factor binding sites. Biological studies are underway to elucidate the biological mechanisms involved and identify if these polymorphisms are indeed the causative mutations.

\section{ACKNOWLEDGMENTS}

We acknowledge the Irish Cattle Breeding Federation (Bandon, Cork, Ireland) for their valuable contribution to this project. We also thank David Magee (University College Dublin, Ireland) for his technical assistance. This research was funded by the Food Institutional Research Measure (06RDTMFRC437) and Research Stimulus Fund (RSF-06-0353; RSF-06-0409) from the Department of Agriculture, Food and Fisheries, Ireland and the Irish Dairy Research Trust.

\section{REFERENCES}

Adachi, K., T. Tanaka, H. Saito, and T. Oka. 1999. Hormonal induction of mouse selenocysteine transfer ribonucleic acid (tRNA) gene transcription-activating factor and its functional importance in the selenocysteine tRNA gene transcription in mouse mammary gland. Endocrinology 140:618-623.

Berry, D., F. Kearney, and B. Harris. 2009. Genomic selection in Ireland. Proceedings of the Interbull International workshop, Uppsala, Sweden.

Berry, D. P., L. Shalloo, A. R. Cromie, R. F. Veerkamp, P. Dillion, P. R. Am, J. F. Kearney, R. D. Evans, and B. Wickham. 2007. The economic breeding index: A generation on. Pages 29-34 in Technical Report to the Irish Cattle Breeding Federation. Irish Cattle Breeding Federation, Bandon, Cork, Ireland.

Bruzelius, K., T. Hoac, R. Sundler, G. Onning, and B. Akesson. 2007. Occurrence of selenoprotein enzyme activities and mRNA in bovine mammary tissue. J. Dairy Sci. 90:918-927.

Close, M. J., A. R. Howlett, C. D. Roskelley, P. Y. Desprez, N. Bailey, B. Rowning, C. T. Teng, M. R. Stampfer, and P. Yaswen. 1997. Lactoferrin expression in mammary epithelial cells is mediated by changes in cell shape and actin cytoskeleton. J. Cell Sci. 110:2861-2871.

Daly, M., P. Ross, L. Giblin, and F. Buckley. 2006. Polymorphisms within the lactoferrin gene promoter in various cattle breeds. Anim. Biotechnol. 17:33-42.

Eckert, D., S. Buhl, S. Weber, R. Jager, and H. Schorle. 2005. The AP-2 family of transcription factors. Genome Biol. 6:246. 
Gilmour, A. R., B. R. Cullis, S. J. Welham, and R. Thompson. 2009. ASREML Reference Manual. New South Wales Agriculture, Orange Agricultural Institute, Orange, NSW, Australia.

Gonzalez-Chavez, S. A., S. Arevalo-Gallegos, and Q. Rascon-Cruz. 2009. Lactoferrin: Structure, function and applications. Int. J. Antimicrob. Agents 33:301.

Harris, B., and D. Johnson. 1998. Approximate reliability of genetic evaluations under an animal model. J. Dairy Sci. 81:2723-2728.

Hill, W. G., and A. Robertson. 1968. Linkage disequilibrium in finite populations. Theor. Appl. Genet. 38:226-231.

Jager, R., U. Werling, S. Rimpf, A. Jacob, and H. Schorle. 2003 Transcription factor AP-2gamma stimulates proliferation and apoptosis and impairs differentiation in a transgenic model. Mol. Cancer Res. 1:921-929.

Johnson, W., and J. L. Jameson. 1999. AP-2 (activating protein 2) and Sp1 (selective promoter factor 1) regulatory elements play distinct roles in the control of basal activity and cyclic adenosine $3^{\prime}, 5^{\prime}$-monophosphate responsiveness of the human chorionic gonadotropin-beta promoter. Mol. Endocrinol. 13:1963-1975.

Kamiński, S., K. Oleński, P. Brym, T. Malewski, and A. A. Sazanov. 2006. Single nucleotide polymorphism in the promoter region of the lactoferrin gene and its associations with milk performance traits in Polish Holstein-Friesian cows. Russ. J. Genet. 42:924-927.

King, A. E., H. O. Critchley, and R. W. Kelly. 2003. Innate immune defences in the human endometrium. Reprod. Biol. Endocrinol. $1: 116$.

Kolm, G., D. Klein, E. Knapp, K. Watanabe, and I. Walter. 2006. Lactoferrin expression in the horse endometrium: Relevance in persisting mating-induced endometritis. Vet. Immunol. Immunopathol. 114:159-167.

Kuss, A. W., J. Gogol, and H. Geidermann. 2003. Associations of a polymorphic AP-2 binding site in the 5'-flanking region of the bovine beta-lactoglobulin gene with milk proteins. J. Dairy Sci. $86: 2213-2218$

Li, G. H., Y. Zhang, D. X. Sun, and N. Li. 2004. Study on the polymorphism of bovine lactoferrin gene and its relationship with mastitis. Anim. Biotechnol. 15:67-76.

Li, Y., G. V. Limmon, F. Imani, and C. Teng. 2009. Induction of lactoferrin gene expression by innate immune stimuli in mouse mammary epithelial HC-11 cells. Biochimie 91:58-67.

Liu, Z., J. Jaitner, F. Reinhardt, E. Pasman, S. Rensing, and R. Reents. 2008. Genetic evaluation of fertility traits of dairy cattle using a multiple-trait animal model. J. Dairy Sci. 91:4333-4343.

Lopes, F. L., J. Desmarais, S. Ledoux, N. Y. Gevry, P. Lefevre, and B. D. Murphy. 2006. Transcriptional regulation of uterine vascular endothelial growth factor during early gestation in a carnivore model, Mustela vison. J. Biol. Chem. 281:24602-24611.

Lum, L. S., P. Dovc, and J. F. Medrano. 1997. Polymorphisms of bovine beta-lactoglobulin promoter and differences in the binding affinity of activator protein-2 transcription factor. J. Dairy Sci. 80:1389-1397.

Malewski, T., M. Gajewska, T. Zebrowska, and L. Zwierzchowski. 2002. Differential induction of transcription factors and expression of milk protein genes by prolactin and growth hormone in the mammary gland of rabbits. Growth Horm. IGF Res. 12:41-53.

Nakajima, K., M. Nakamura, X. D. Gao, and T. Kozakai. 2008. Possible involvement of prolactin in the synthesis of lactoferrin in bovine mammary epithelial cells. Biosci. Biotechnol. Biochem. 72:1103-1106.

O'Halloran, F., B. Bahar, F. Buckley, O. O'Sullivan, T. Sweeney, and L. Giblin. 2009. Characterisation of single nucleotide polymorphisms identified in the bovine lactoferrin gene sequences across a range of dairy cow breeds. Biochimie 91:68-75.

Olori, V. E., T. H. Meuwissen, and R. F. Veerkamp. 2002. Calving interval and survival breeding values as measure of cow fertility in a pasture-based production system with seasonal calving. J. Dairy Sci. 85:689-696.

Pryce, J. E., and R. F. Veerkamp. 2001. The incorporation of fertility indices in genetic improvement programmes. Pages 223-236 in Fertility in the High-Producing Dairy Cow. M. G. Diskin, ed. Occ. Publ. No. 26, Br. Soc. Anim. Sci., Edinburgh, UK.

Safe, S., and K. Kim. 2008. Non-classical genomic estrogen receptor (ER)/specificity protein and ER/activating protein-1 signaling pathways. J. Mol. Endocrinol. 41:263-275.

Seyfert, H. M., A. Tuckoricz, H. Interthal, D. Koczan, and G. Hobom. 1994. Structure of the bovine lactoferrin-encoding gene and its promoter. Gene 143:265-269.

Stephens, M., and P. Donnelly. 2003. A comparison of Bayesian methods for haplotype reconstruction from population genotype data. Am. J. Hum. Genet. 73:1162-1169.

Stephens, M., N. J. Smith, and P. Donnelly. 2001. A new statistical method for haplotype reconstruction from population data. Am. J. Hum. Genet. 68:978-989.

Teng, C. T. 2002. Lactoferrin gene expression and regulation: An overview. Biochem. Cell Biol. 80:7-16.

Teng, C. T., C. Beard, and W. Gladwell. 2002a. Differential expression and estrogen response of lactoferrin gene in the female reproductive tract of mouse, rat, and hamster. Biol. Reprod. 67:1439-1449.

Teng, C. T., W. Gladwell, C. Beard, D. Walmer, C. S. Teng, and R. Brenner. 2002b. Lactoferrin gene expression is estrogen responsive in human and rhesus monkey endometrium. Mol. Hum. Reprod. 8:58-67.

Walsh, S., F. Buckley, D. P. Berry, M. Rath, K. Pierce, N. Byrne, and P. Dillon. 2007. Effects of breed, feeding system, and parity on udder health and milking characteristics. J. Dairy Sci. 90:57675779 .

Walsh, S., F. Buckley, K. Pierce, N. Byrne, J. Patton, and P. Dillon. 2008. Effects of breed and feeding system on milk production, body weight, body condition score, reproductive performance, and postpartum ovarian function. J. Dairy Sci. 91:4401-4413.

Wang, H. M., Z. X. Kong, C. F. Wang, J. M. Huang, Q. L. Li, M. H. Hou, J. B. Li, and J. F. Zhong. 2009. (Genetic polymorphism in 5 '-flanking region of the lactoferrin gene and its associations with mastitis in Chinese Holstein cows.) Yi Chuan 31:393-399. In Chinese

Wang, S. R., J. Lin, I. C. Cheng, and T. Y. Lin. 1998. Characterization and functional analysis of the porcine lactoferrin gene promoter. Gene 215:203-212.

Wang, S. R., T. Y. Lin, C. M. Chen, and C. N. Weng. 1997. Isolation and expression of a porcine lactoferrin gene. Am. J. Vet. Res. 58:1152-1158.

Wang, Y., Y. Tu, F. Han, Z. Xu, and J. Wang. 2005. Developmental gene expression of lactoferrin and effect of dietary iron on gene regulation of lactoferrin in mouse mammary gland. J. Dairy Sci. 88:2065-2071.

Weller, J. I., and E. Ezra. 1997. Genetic analysis of somatic cell score and female fertility of Israeli Holsteins with an individual animal model. J. Dairy Sci. 80:586-593.

Yanaihara, A., K. Mitsukawa, S. Iwasaki, K. Otsuki, T. Kawamura, and T. Okai. 2007. High concentrations of lactoferrin in the follicular fluid correlate with embryo quality during in vitro fertilization cycles. Fertil. Steril. 87:279-282.

Zhang, J., S. Brewer, J. Huang, and T. Williams. 2003. Overexpression of transcription factor AP-2alpha suppresses mammary gland growth and morphogenesis. Dev. Biol. 256:127-145.

Zheng, J., J. L. Ather, T. S. Sonstegard, and D. E. Kerr. 2005. Characterization of the infection-responsive bovine lactoferrin promoter. Gene 353:107-117. 